\title{
Perceptions of a New Medium: Gifted Children Think About Computers
}

\author{
S. C. Sesko
}

This paper was prepared for submittal to the

The Annual Conference of the American Educational Research Association

Montreal, Quebec, Canada

April 19-23, 1999

April 12, 1999

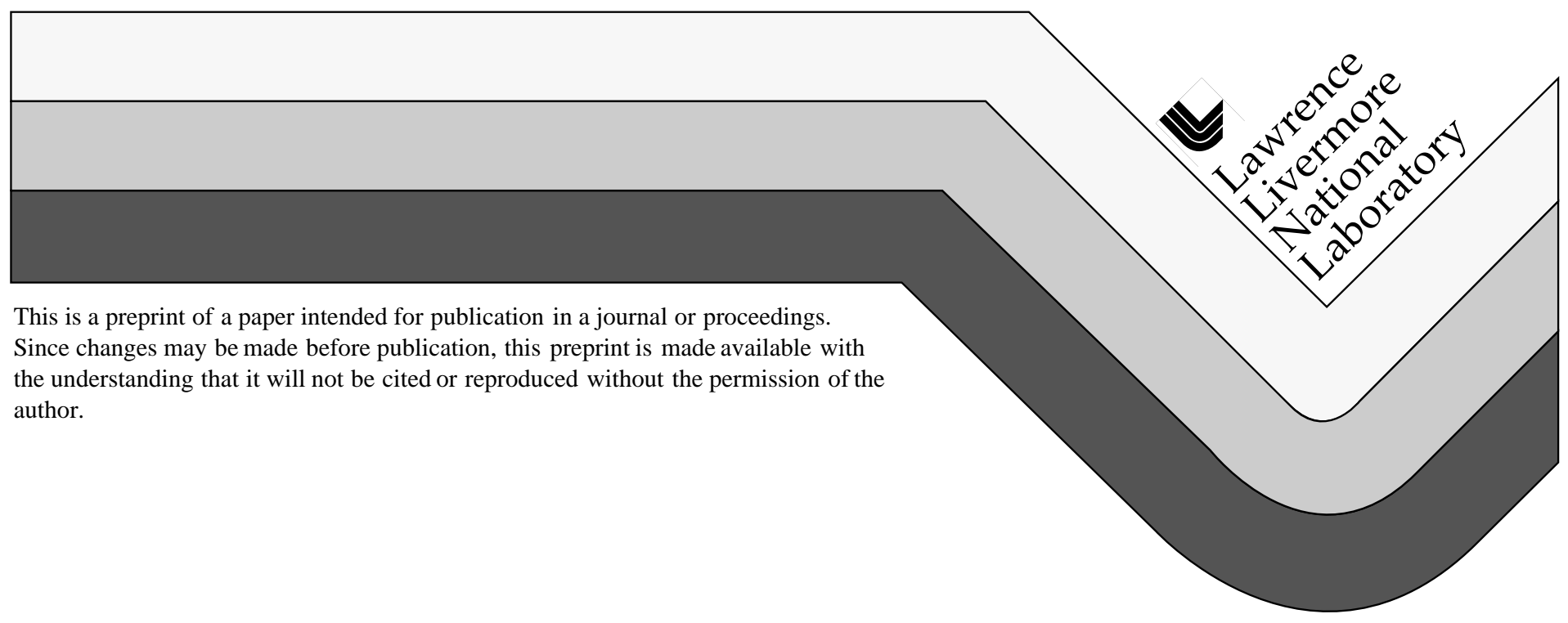




\section{DISCLAIMER}

This document was prepared as an account of work sponsored by an agency of the United States Government. Neither the United States Government nor the University of California nor any of their employees, makes any warranty, express or implied, or assumes any legal liability or responsibility for the accuracy, completeness, or usefulness of any information, apparatus, product, or process disclosed, or represents that its use would not infringe privately owned rights. Reference herein to any specific commercial product, process, or service by trade name, trademark, manufacturer, or otherwise, does not necessarily constitute or imply its endorsement, recommendation, or favoring by the United States Government or the University of California. The views and opinions of authors expressed herein do not necessarily state or reflect those of the United States Government or the University of California, and shall not be used for advertising or product endorsement purposes. 


\title{
Perceptions of a new medium: Gifted children think about computers
}

\author{
Stephen C. Sesko, Ph.D. \\ Science \& Technology Education Program \\ Lawrence Livermore National Laboratory
}

This work was performed under the auspices of the U.S. Department of Energy by Lawrence Livermore National Laboratory under Contract W-7405-Eng-48.

\begin{abstract}
The purpose of this study was to begin to investigate the cognitive and affective attitudes that gifted students have about computers. As a teacher of gifted students in the field of computer programming, I wanted to learn what these students thought about the machine as a part of their lives. I discovered that it is far more current than I had thought. The computer is as important to these students as is the telephone, television, the microwave, or any other appliance. I also learned that unlike these other appliances, the computer is far more useful and interconnected to these students. It is not a substitute for friends or family, but it is a partner in many of the things that these students do for fun, work, or for profit.

\section{Introduction}

In this study I investigated the affective and intellectual views of the computer held among gifted children who use computers extensively. The study is an outgrowth of previous research (Sesko, 1998). The objective of this study is to explore the meaning that computers have in the lives of these specifically identified gifted children: What epistemic foundations have these children established for themselves regarding how they use computers and knowledge? I delineated seven questions for which I sought answers:

1) What were the circumstances that brought about an interest in computers for these children?

2) Where and how did they begin using computers; and what were their early experiences like?

3) How do these gifted children think they have achieved their current level of understanding of computer use?

4) How long do they think it took to achieve the level of proficiency they believe they are at?

5) What perceptions do they have of their own skill level using computers, relative to peers, relative to adults, and relative to other things they know? Do they consider themselves to be experts? Do they exhibit any of the attributes of experts?

6) How do these children describe the various uses they have found for computers? What other descriptions might apply?

7) What meaning does the computer have in their lives? What epistemic foundations have they established for themselves regarding computers and knowledge? To what extent are they engaged with computer usage?
\end{abstract}




\section{Literature}

A major reason for this and the 1998 study is that relatively little research in the area of gifted and talented children has addressed computers and learning. Literature searches several years apart -- and as late as June 1998 -- for studies in this area produced few research papers, none of which addressed the question in this study. Further, except for one study (Shrock, \& Stepp, 1991), researchers have not looked at children who, with experience on home computers, have achieved a high level of expertise in computer applications and/or computer programming outside the classroom. Not that the field is barren. One need only look at perhaps the most important foundational work that informs this study, Turkel's The Second Self (1984), to see the fascination inherent in this topic.

The intellectual characteristics of gifted children suggest that those who are interested in computers are enabled to achieve a high level of proficiency with either computer applications or programming. Further, the ability to learn things at a young age should allow gifted children who use computers to develop a large variety of computer-based activities. However, no published evidence has been found previously to support either thesis.

Finally, as Hausman (1985) claims, facility with computers should allow these children to create new activities for using computers, but I found no published research to demonstrate whether they do. I believe, however, that the results of this study would be pleasing to Hausman; it is this kind of creativity that is evidenced in this research.

\section{Methodology and Participants}

The data come from interviews with four gifted children, from observations of their work at the computer, and from reading their journals, book lists, and other written materials. The students were selected based on the profile of computer using gifted children described in Sesko (1998). Supporting data come from adults who know the four primary participants and from a second group of twelve gifted computer-using students. These data do not describe all gifted children, or all gifted children who are interested in computers. The sample was neither scientific nor typical, nor was it intended to be; these children were all self-selected.

The research methodology followed standard qualitative procedures in interviewing, data synthesis, evaluation, and reporting. I followed the works of Farrell, Peguero, Lindsey, and White (1988), Fine and Sandstrom (1988), Horney and Healey (1991), McCracken (1988), Wolcott (1990), and Yin (1989).

The research data from this study are presented in the form of stories edited data from the interviews conducted with each participant, along with comments on their journal entries, their book lists, and comments from the adults who remarked on three of the children. Taken together, the data create a rich description of the interactions these students have had with computers, from their first experiences to the time of the interviews. The stories develop both cognitive and affective aspects of the participants' computer use. The stories also have sub-themes, reflecting the codes that were developed in a group discussion. Each participant is presented alone, from the oldest to the youngest, thus allowing for indications of change over time. 
The participants are:

Erik is a 16 year old junior in high school. Erik is a perfectionist who frets a lot. He prefers the word "worry," but both are good descriptors. He describes himself as coming from a lower middle class family. His father works in a glass factory as a packer; he has some high school education. His mother is a high school graduate, who does volunteer work.

Erik has always taken the advanced classes in high school, and is now in precalculus. He has a cumulative grade point average of 4.0 (all A's). Erik's school activities include working for the basketball team, the local honor society, and the Spanish club. Erik holds an appointed office in the school government, technology coordinator. He was recently elected as the student body president, the first big office for which he has run. He does not participate in sports, but he is an avid fan. He does not participate in music, but enjoys listening to radio and recordings. He prefers classical music.

At thirteen, Enrique is the older of the middle school students. He is the most serious of the four participants, quiet and reflective. He comes from a middle class family. His father works as a systems programmer. He has some college education, but never completed his degree in engineering. His mother has a high school education and a paralegal certificate from a community college. Enrique has a younger brother with whom he works on computers.

Enrique is in eighth grade, his last year of middle school. This year he is taking algebra and advanced history, the only advanced classes available in eighth grade. He, like Martha, has selected German as his foreign language. His grades at the time of the interviews were all A's, except for a B in German.

Enrique is actively involved in Boy Scouts and he is very proud of his accomplishments in this area--20 merit badges, only two more for Life Scout, and five for Eagle. His peers have elected him to the positions of Patrol Leader and Senior Patrol Leader. He is a member of the Order of the Arrow, a group of elite campers, and he has been chosen for leadership training.

Music is another area of interest. He has had piano lessons, but has not continued with them. He has played clarinet for four years and bass guitar for two years. He is in his school's jazz band. Enrique recently joined the wrestling team at school. He also enjoys ice-skating and street hockey.

Martha, the younger of the two middle school participants, describes herself as "four feet 11 inches short." She comes from a middle to upper middle class family. Her father is a professional with a college degree who works as a hydrogeologist. Her mother has some college education. She volunteers frequently in the schools.

Martha is 12 years old and in the seventh grader. Her recent grades were all A's. She is taking pre-algebra and German, but she considers her schedule to be easy. Martha has been elected to the student council and to the school site council. The latter includes parents, faculty, and administration. She participates in swimming in the summer and soccer in the fall. In school she plays oboe, while privately she is in the Suzuki violin program. Martha belongs to the 4-H Club, where she is interested in leather craft and photography. 
The youngest participant is Paul. He comes from a middle to upper middle class family. Both parents are professional people with college degrees. His father is a real estate appraiser and his mother is a high school teacher.

Paul was 11 when the interviews began, and has since turned 12. He is in sixth grade, the last year of elementary school in his district. His recent grade report was all A's, except for a B in math, which surprised even him, because of his strong interest in that subject.

Paul is the most athletic among the four participants. He takes part in basketball, baseball, and soccer. In the summer he enjoys camping, fishing, and swimming. In winter, he goes skiing and ice-skating. Most recently, he has taken up street hockey. Paul enjoys all games, particular video games and board games. His mother describes him as being very good in chess, for his age.

\section{Data and Discussion}

This discussion is organized to follow each of the questions for which I sought answers. While this discussion speaks mostly to the data from the four primary research participants, the data from the eight secondary participants confirmed what is written here.

The first question was designed to discover the circumstances that brought about an interest in computers for these children. Erik was enchanted by a game at school. Enrique became interested because of the work his father does. Martha seems to have been prompted by her family; she, alone, seemed to have no intrinsic interest in learning about computers. Paul only remembers it being a part of his life for as far back as he can remember.

The purpose of the second question was to find out where and how they began using computers, and what their early experiences were like. The survey data led to an assumption that all of the students had begun their work with computers at home (Sesko, 1998). Actually, this was the case only for Enrique and Paul. The other two students were first exposed to the computer at school. But further data from the survey and the interviews seem more to the point. The important information is not so much where the students had their first experiences with computers, as it is where they have learned the most about computers. In this light, all of the students agree that they have learned the most at home or in another venue outside of school. Of the secondary participants, two had their first experiences at school. Six had their first experiences at home.

All four learned word processing at home, and in response to being assigned papers at school. All eight of the secondary participants learned at home.

Only three are familiar with databases. Erik and Enrique learned about them at home; Paul was only exposed to them at school, with no real depth. Three of the secondary participants are familiar with databases, one middle school and two high school students. All three learned at home.

Erik learned spreadsheets at home; the other three have yet to be exposed to this application. Of the secondary participants, one from elementary school, one from middle school, and all three of the high school students are familiar with spreadsheets. Two of the high school students learned them at home; the other three students were exposed to them at school, but with no real instruction. 
Only three are familiar with telecommunications. Erik and Enrique learned about it at home; Paul was only exposed to it at school, with no real depth. Among the secondary participants, one elementary student, one middle school, and two high school students are familiar with telecommunications. The two younger ones were exposed to the application in school, but only exposed, no real instruction. The two high school students learned at home.

All four learned graphics at home, mostly for fun, rather than for a specific use or need. Six of the eight secondary participants are familiar with graphics; all learned at home with the exception of one of the high school students, who learned in school while working on the school newspaper.

Only two are familiar with HyperCard. Erik had classes at school, but he considered them very inadequate; Martha learned elsewhere. Three of the secondary participants are familiar with HyperCard. They all learned at home.

Enrique learned programming at home; the other three learned elsewhere. The existence of a computer education program outside of their schools was important for these three. Would they have learned programming at such an early age had it not been for that program? Their testimony says "No." This was confirmed by all eight of the secondary participants, all of whom learned outside of school.

With the exception of Paul, who enjoys almost everything, the participants found their elementary school experiences with computers to be boring. They had little or no instruction in the use of computers and spent what little time was available each week playing games. The games seemed to be the same ones every year. Elementary school classes were all conducted in a computer lab. The regular classroom teacher did not go with the students, so the games were, for the most part, uncoordinated to the regular classroom lessons. The quality of the lab coordinator was inconsistent. The secondary participants all made comments similar to the four main students. Games were the main activity for all eight of the students; thus the three high school students had the same experience as Erik. The three who are in middle school now experienced the same games as Enrique and Martha. The two who are in elementary school now are still using the same kinds of games that have been used by all of the older students. Only one elementary school student indicated that his class did something other than games. His class has had some interaction with telecommunications about twenty percent of the time.

The two middle school students, Enrique and Martha, were not able to distinguish any improvement in computer instruction when they got to middle school. For this reason, they both stopped computer classes after the required class in typing in sixth grade. Erik had no exposure to computers in middle school. One of the secondary high school students also had no computers in middle school. The other two high school students and the three who are in middle school now all indicated that middle school computer classes consisted of required typing instruction in sixth grade. Seventh and eighth grade classes consisted of six-week introductions to word processing and, in one school, Logo.

Erik has had access to computers in high school, but, in his opinion, the instruction available for an advanced student like him is either very poor or non- 
existent. Two of the secondary high school students have had no classes in computers. One student was able to take BASIC and Pascal.

Questions three and four were concerned with how these gifted children think they have achieved their current level of understanding of computer use, and how long it took. Without exception, all of the students believe that they have reached their current level of understanding by continually working with the computer. They also believe there is a difference between learning applications and learning programming. Applications seem to be mechanical activities that simply require learning a set of commands and keyboard actions. The students believe that these learning activities can be accomplished in a rather short amount of time, if they have that time to spend. Programming, on the other hand, is something that takes longer. Programming seems to be a subject that is constantly developing. Of the secondary participants, the elementary school students had no comments in this area. The middle and high school students agreed with the four main participants.

The major theme in this section is that it takes a lot of practice to become good at something. Here there is a connection to Bloom's concepts of automaticity. These students are all self-taught. They have worked hard at their computer learning at home, because the skills that they were interested in acquiring were not offered to them at school.

They achieved their current understanding by working at it, by practice, and by spending time at doing whatever the application required. Erik has developed a network that helps to inform his learning. By inference from the previous testimony, Enrique has probably done the same. Martha has not developed the same depth of a network, relying mostly on her Mother for instruction. Only one of the secondary students, a high school senior, mentioned the kinds of support systems just described.

The fifth question sought the students' perceptions of their own skill level using computers, relative to peers, relative to adults, and relative to other things they know. All of the students consider themselves to be better than their peers in the various applications that they know. In programming, only Erik and Enrique definitely consider themselves better than their peers. Martha and Paul are more ambivalent. They know they are better than some students, but perhaps not as good as others. Compared to adults, all of the students think they are better at applications and programming than most adults, but they are well aware that they know less than adults who are familiar with computers. Only Erik and Paul commented that they know computers better or less than specific school subjects. Of the eight secondary participants, the two elementary school students both felt that they did not know as much as their peers, and certainly less than adults. Of the three middle school students, one felt better than peers and most adults. The other two felt at least equal to their peers. At the high school level, one student felt superior to peers and most adults. The other two indicated they knew at least as much, if not more than their peers, but less than adults.

Question five also asked if the students consider themselves to be experts in the various applications and programming. Only Erik and Enrique answered this question in the affirmative, and only for programming in the languages with which they are most familiar. Only one of the secondary participants said the same--the 
same high school senior mentioned above. None of the students considered themselves to be experts with applications; they all said they have a lot more to learn about the various applications. Martha and Paul said the same for programming. None of the secondary participants considered themselves expert in applications, except the high schooler already mentioned. This student felt expert in graphics.

There is a large amount of quiet confidence among these students, even in Martha, who judges her own abilities only in comparison to those of others. Erik, Martha, Paul, and Enrique are satisfied with what they know. The same can be said for the eight secondary participants.

Question five also sought to know whether their interactions embody any, or all, the attributes of experts. The answer to this question is complex. Both Erik and Enrique show some of the attributes of experts, but not all, or even a large number. Erik has the ability to see relationships between and among the languages with which he is most familiar, but has yet to extrapolate this knowledge to ones he is just beginning to learn. The same can be said of his ability to look beyond the surface elements of a programming problem. Enrique is extremely familiar with the technical terminology of his languages, but he is just beginning to go beyond the surface.

These students have an intuitive knowledge of what they think an expert is, or should be. They recognize the need to know several programming languages, and to know them in depth. They see a need to know other applications in depth, so that they, "can do a variety of things, quickly," as Erik puts it. There is also a humanistic side to expertise that shows up in Martha's comments that is missing from the research literature. It is a characteristic of expertise that she thinks is worth developing, the ability to help other people.

The secondary participants did not respond to this last part of question five, and no real-time interviews were done from which observation data could be taken.

Question six looked at how these children describe the various uses they have found for computers. The guides for this question were amplifier versus cognitive reorganizer and first-order effects versus second-order effects. The interview results on this question are complex. All of the students use applications as an amplifier to some degree. Martha's uses of applications are almost exclusively in the amplifier mode. Paul is beginning to see that applications offer him a source of powerful tools that can change the way he thinks about information and how to use and present information. Both Erik and Enrique are fully aware of this power, but seem to have few opportunities to use it to the best extent. Enrique sees some applications as new and powerful modes of creativity and self-expression.

The secondary students all mentioned amplifier activities similar to those of the main participants. There were no indications of cognitive changes or secondorder effects in the short interviews that were conducted. Without more extensive interviews with these eight students, it would be unwise to say that they definitely do or do not exist.

Programming is the one area where second order effects are beginning to be seen. Enrique's demonstrates these effects very well in many of the things he does. Erik shows these effects, but has trouble admitting that they are any different from 
other things that he does. At least he does not attribute these changes to his use of the computer. Paul is just beginning to show changes in the way he works with the computer. Martha has not yet reached this level.

The same comment made above applies here, also.

Question six was designed to gather cognitive data. However, another part of the question asked if there are other descriptions might apply. There were a lot of data to indicate the presence of a strong affective element as well.

This affective element is a more intuitive and emotional way of viewing the world. However, to view these children as complete human beings, we must not discount this aspect of their personalities. After all, learning is not always a mental thing; what happens on the attitudinal level is also important.

Four major affective themes emerged from the interviews. The most prevalent statement was that working with the computer is fun. These students enjoy most everything about the computer, games, exploring new and familiar applications, programming, and even typing. They made no similar comments about other subjects. All eight of the secondary participants agreed with the idea of fun.

The social aspect was also very strong. They see the computer as a way to meet other kids. It is something that is unique that they have in common with other users, something apart from the ordinary. The computer is something that sets them apart from others. It is almost an exclusive club, but they will let anyone in who meets the requirements. The elementary school students in the secondary interviews agreed with the social aspect of computers, as did one of the middle school students. The others had no comments in this area. It should be noted, however, that one of the high school students finds family involvement to be strong, as did Enrique.

The computer is a mode of creative expression, both in the way that products look when they are completed, and in the things that the computer allows them to do that they may not be able to do with non-computer media. Martha, in particular, speaks of the aesthetic appeal of computer products.

The idea of a sense of accomplishment is very strong. The satisfaction of accomplishing something with the computer is heightened by the fact that they have learned to do it by themselves. All eight of the secondary participants agreed with this theme, especially with regard to programming.

Question seven sought information on the epistemic foundations the students have established for themselves regarding computers and knowledge. All of the students, including the secondary participants, made distinctions between what they learn with and about computers and what they learn in school. School is a place where things are memorized and seem to have little interest to the students, because they see no place to use what they have learned. Computers, on the other hand, are of great interest to both the four main students and all eight of the secondary participants. Because it is something they want to do, they are more involved and interested. Again, they see school as a place where they learn facts that seem to have no application. School is a place where the same thing seems to go on year after year. Learning computers is a process that is continuously changing and building. 
The last question also sought information on the extent to which the students are engaged in their use of computers. All of these participants are very intrinsically motivated to learn and work with computers. They either indicate, or say outright, that they are their own motivation. They learn because they want to and the work on the computer because they want to. The two high school participants who gave confirming interviews gave similar statements. The other six did not have comments on this theme.

Finally, the last research question sought information on the meaning computers have in the lives of these children. Erik shows the kind of growth and development that can take place over the years. He began thinking of the computer as a magic little box, and now sees it as an integral part of his future. Enrique has come to the same conclusion. He, too, knows that the computer will be important to him in what he does in the future. The younger students see the computer as important to who they are right now. Martha, particularly, enjoys knowing something that others do not. From a source of fun, a cure for boredom, to a future profession, it seems clear that the computer is a very important part of the lives of these children. The other gave comments similar to these eight. The elementary school students said things similar to Paul's comments. The high school students all see computers in their future employment, as does Erik. The middle school students gave answers similar to those of Enrique and Martha.

\section{End Note}

The study led to several conjectures about the interactions of gifted children and computers. These children have constructed their own ideas of what computers are for and what they are able to do with them. Though many of these uses are no different from the ones that other children and adults have found for computers, the study found some idiosyncratic uses and meanings. Because of their facility with the machine, the students indicate they have found new ways of working. These ways of working have both cognitive and affective elements. The cognitive is seen in the different ways the students use and think about the computer for school and personal uses. The affective element is seen in themes such as fun, social interactions, and rewards.

In this work, I found that these students believe that the computer allows them to learn and to accomplish tasks in ways that are unlike what is expected of them in school. They approach the computer by exploring and by finding ways to fit it into their everyday lives. For these students, the computer has "always been there." It is a meaningful part of their lives.

Along with the "what" of research, there is the question of "why" it is important and worth pursuing. This study establishes, to the best of the writer's knowledge, a precedent in the field of research into gifted and talented children and their use of computers. This research has the promise of contributing to knowledge in the area of gifted and talented education, in that, by understanding better how gifted children come to learn about the computer, by understanding better the uses they have for the machine, and by understanding what gifted children think about the machine, educators may be able to develop curricula, environments, and instruction to enhance these learning experiences. 
References and Bibliography

Adelson, B. (1981). Problem solving and the development of abstract categories in programming languages. Memory and Cognition, 9 422-433.

(1984). When novices surpass experts: The difficulty of a task may increase with expertise. Journal of Experimental Psychology: Learning, Memory, and Cognition, 10, 483-495.

Bloom, B. (1986). The hands and feet of genius: Automaticity. Educational Leadership, February, 70-77.

Clark, B.. (1991). Growing up gifted: Developing the potential of children at home and at school, (4th ed.). New York: Merrill.

Farrell, E., Peguero, Lindsey, \& White. (1988). Giving voice to high school students: Pressure and boredom, ya know what I'm sayin'? American Educational Research Journal, 25 (4), 489-502.

Fine, G. A., \& Sandstrom, K. L. (1988). Knowing children: Participant observation with minors. Sage University Paper Series on Qualitative Research Methods, Vol. 15. Beverly Hills, CA: Sage Publications.

Hausman, C. R. (1985). Can computers create? Interchange, 16 (1), 27-37.

Horney, M., \& Healey, D. (1991) Hypertext and database tools for qualitative research. AERA, April 1991, Chicago.

McCracken, G. (1988). The long interview. Sage University Paper Series on Qualitative Research Methods, Vol. 13. Beverly Hills, CA: Sage Publications.

McKeithen, K. B., \& Reitman, J. S. (1981). Knowledge organization and skill differences in computer programmers. Cognitive Psychology, 13, 307-325.

Pea, R. D. (1985). Beyond amplification: Using the computer to reorganize mental functioning. Educational Psychologist, 4, 167-182.

Perkins, D. (1985). The fingertip effect: How information processing technology shapes thinking. Educational Researcher, 14 (7), 11-17.

Sesko, S. C. (1998). Patterns of computer use among gifted children. AERA, April San Diego.

Shrock, S. A., \& Stepp, S. L. (1991). The role of the child microcomputer expert in an elementary classroom: A theme emerging from a naturalistic study. Journal of Research on Computing in Education, 23 (4), 545-559. 
Turkle, S. (1984). The second self: Computers and the human spirit. New York: Simon and Schuster.

Wolcott, H. F. (1990). Writing up qualitative research. Sage University Paper Series on Qualitative Research Methods, Vol. 20. Beverly Hills, CA: Sage Publications.

Yin, R. K. (1989). Case study research: Design and methods. Sage University Paper Series on Applied Social Research Methods, Vol. 5. Beverly Hills, CA: Sage Publications. 